\title{
Innovative sound device that repel monkeys and its scientific validation in Jammu
}

\section{RK Gupta*}

Division of Entomology, SK University of Agricultural Sciences and Technology, Jammu Chatha, India

*Corresponding Author: RK Gupta, Division of Entomology, SK University of Agricultural Sciences and Technology, Jammu Chatha, India. Received: May 10, 2019; Published: June 21, 2019

DOI: 10.31080/ASAG.2019.03.0540

Increasing human- animal conflicts are posing enormous threat to food insecurity for small resource poor hilly farmers living in and around traditional forest areas. A recent survey undertaken in Hill agriculture including Jammu and Kashmir suggested that many affected residents believe five major problems viz dwindling water resources and dry spells, invasion by exotic weeds like Lantana and Parthenium in pastures and grazing lands, Rhesus monkey menace and diminishing returns from agro commodities that have worsened the livelihood of farmers, leading to large scale migration and leaving families dependent on state-subsidised food rations. The worst sufferer of monkey menace is hilly states viz Himachal Pradesh, Jammu and Kashmir and Uttarakhand. Nevertheless, other states like Rajasthan, Karnataka, Tamil Nadu , Bihar and Delhi are also struggling to contain assaults by monkeys [1,2]. The menace has now reached epic proportions with estimated loss of more than 3000 crores in India, While, in Himachal Pradesh direct and indirect damage to farm produce is estimated around Rs.1000 crore annually [3]. In Jammu and Kashmir about 250 villages in Jammu lose farm produce worth Rs 33 crore every year because of attacks by wild monkeys [4]. But it is strongly believed that exact estimates are much higher, around 300 - 500 crores and like Uttarakhand many village residents opt to sell their farmlands than grow crops in Jammu, Samba, Kathua, Reasi, Udhampur, Ramban, Rajouri, and Poonch districts. Besides damaging crops, over hundred people are bitten by monkeys every day and this results in huge expenditure on vaccines for the victims to avoide transmission of many other disease germs like the Herpes B virus10 due to such conflicts [5]. Unlike other countries, Indians have many religious and traditional beliefs about monkeys and their killing is not desired, but frequent conflicts have affected the traditional bond between man and monkey. The current methods of dealing with monkey menace in are inefficient and only contributed to further accelerating the problem. Although, recently Govt have allowed selective killing in some states in India, challenges still remain to develop efficient management and conservation strategies to resolve the man-monkey conflicts. Behavioural ecologists find several issues with translocations of monkey as a solution, while sterilisation programmes did not meet expected results in Himachal Pradesh [6]. A pilot project on oral contraceptives in a 20 square $\mathrm{km}$ area of the tree-lined institute, studying monkey behaviour and food habits is being attempted. Initial results have been found satisfactory, and the scientists are confident that the contraceptive will keep the runaway monkey population down. But unfortunately, the vaccine is not available in India and would cost at least Rs 6,000 which is beyond the economic access of common farmer $[7,8]$ Come what may, traditional and conventional ways will continue to remain crucial for the farmers in hilly region who are still practicing string to through stones (Gulail) and noise making methods like drum beating and firecrackers etc.

In an effort to find solution, we devised an innovative repelling sound device that mimic Baboon barking and validated the same in field situation under Jammu hills. The device was made out of simple metal paint container (1 liter capacity ).The lid of container remained open while a small circular whole $(0.5 \mathrm{~cm}$ dia) was drilled in the centre of its bottom to which a 1 meter long string made of shoe lace was tied through a knot inside (Plate-1). This string is frequently dipped in a water-based solution as and when required and pulled against the bottom every time to produce the sound by holding with one hand while rubbing along the rope with another hand (Video 1). We do not want to disclose the ingredient, but we advocate farmers to use water only for their personal use. The performance of this device was compared with two most commonly used methods in three different locations of village Ramkote in Kathua District of J\&K viz Upper Ramkote, Lower Ramkote and Bhool each comprising $500 \mathrm{~m} 2$ area prone to attack by monkeys. The sound effect and frequency for each measure was also recorded. Each measure was practiced for 5 minute duration followed by an interval of 30 minute. All observations were recorded at the peak hour of activity (11 AM -1 PM) independently from a roof top. The mean numbers of monkey entering the area after each interval of treatment were recorded. After obtaining the preliminary data we distributed ten numbers of such devices to farmers of nearby villages and recorded their response accordingly. 


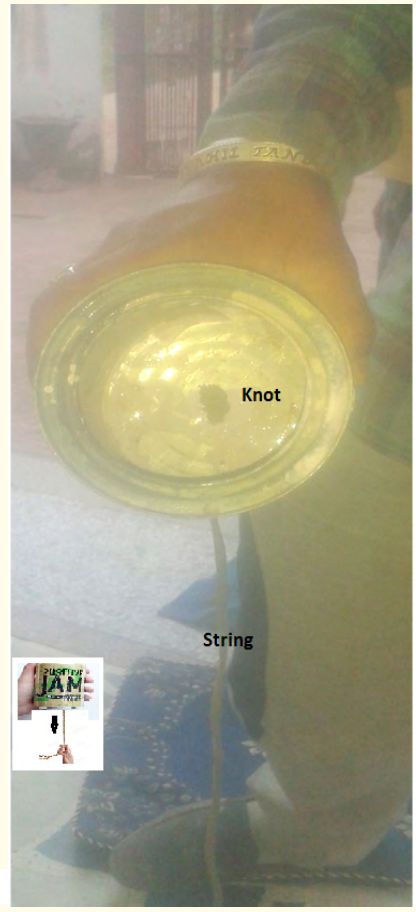

Plate 1

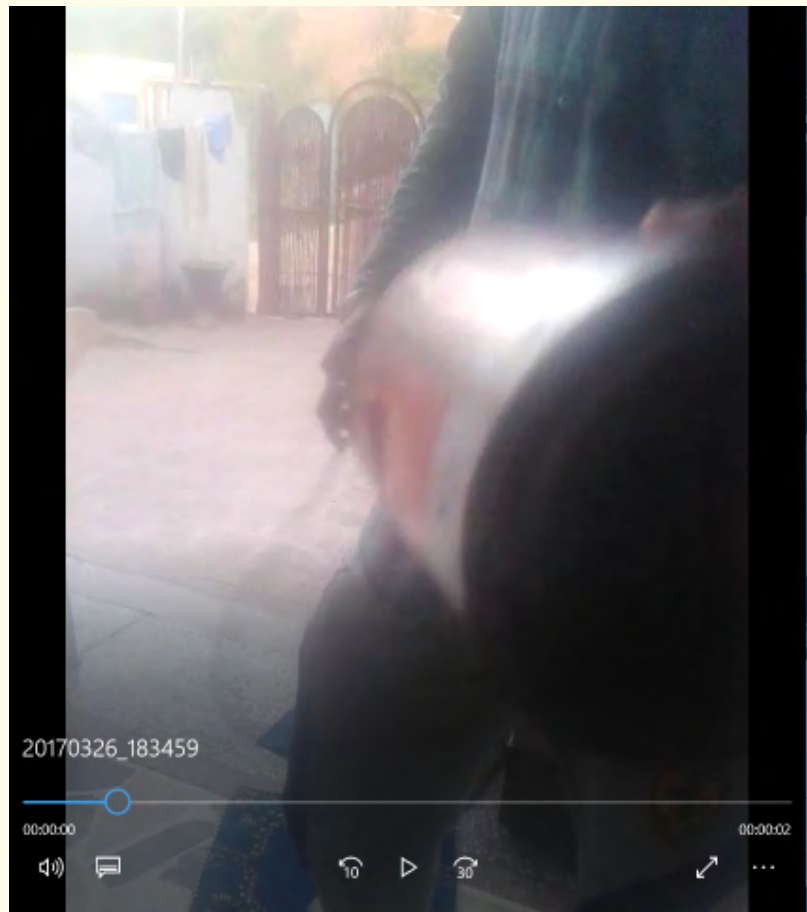

Video 1: Playing monkey repelling sound.
The current device produces a high frequency sound like baboon bark and keeps off the monkeys. When played manually near the monkey herd, all monkeys got excited and nervous and start running away from it. Perceiving the threat of baboon, they also displayed warning sounds to their fellow monkeys. When tested for its comparative efficacy in field situation during peak hours, it was found that all the measures practiced by farmers were helpful in containing the monkey menace but the magnitude of repelling them varied to a greater extent (Table 1 ). However, the currently devised sound device proved the most efficient ( $>99 \%$ repel), cheap $(<10 ₹)$ and very easy to operate even from within the home. All the farmers have rated the performance of device as outstanding. A high-intensity ultrasonic device of 20 - $50 \mathrm{kHz}$ frequency that mimics the sounds of a baboon has already been tested but the monkeys are slowly adapting to this due to its uniform pattern however, the sound emanating from the manually devised sound device can be is
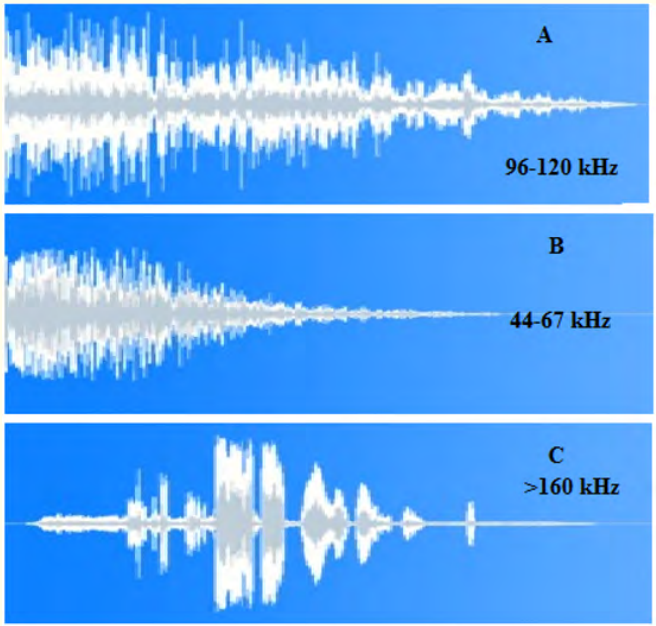

Figure 1: Sound pattern of A. Drum Beat B. Firecracker C. Sound Device

\begin{tabular}{|l|c|c|c|c|c|c|}
\hline \multirow{2}{*}{ Practices } & \multirow{2}{*}{ Duration } & \multirow{2}{*}{ interval } & \multicolumn{2}{c|}{$\begin{array}{c}\text { Total number of monkey that were seen in 500 } \mathbf{~ m}^{2} \\
\text { after each interval (during peak hours) }\end{array}$} & \multirow{2}{*}{ Farmers response } \\
\cline { 4 - 7 } & & & Upper Ramkote & Lower Ramkote & Bhool & \\
\hline Beating drums & $5 \mathrm{~min}$ & $30 \mathrm{~min}$ & 3.6 & 4.3 & 5.6 & Good \\
\hline Fire work & $5 \mathrm{~min}$ & $30 \mathrm{~min}$ & 6.1 & 4.9 & 6.3 & Good \\
\hline Sound device & $5 \mathrm{~min}$ & $30 \mathrm{~min}$ & 0.0 & 0.2 & 0.0 & Outstanding \\
\hline Control (no measure) & nil & nil & 18.3 & 18.4 & 21.1 & Severe damage \\
\hline
\end{tabular}

Table 1: Comparitive efficacy of innovative device against macaque monkey's at three locations in Jammu hills. 
constantly varied through pressure of pulling and therefore monkeys do not easily get acquainted with it over the time.

\section{Acknowledgements}

Author thanks Mr Kungri and his team, GREF complex Ramkote for playing the device and validation support. Thanks, are also due to President Jan Jagran, Ramkote for providing necessary inputs for this study.

\section{Bibliography}

1. Pirta RS., et al. Biological Conservation 79 (1997): 97-106.

2. Chakravartty A. Down To Earth (2015).

3. Khanna P. Early times (2017).

4. Chauhan A and Pirta RS. Journal of Human Ecology 30 (2010,): 105-109.

5. Reddy AR M and Chander. Journal Indian 142 (2016): 941-832.

6. GunasekaranS and Arunachalam S. Current Science 103 (2012): 760.

7. HPFD (2016).

8. Saraswat R., et al. European Journal of Wildlife Research 61 (2015): 435-443.

Volume 3 Issue 7 July 2019

C) All rights are reserved by RK Gupta. 